\title{
NATURAL AND ANTHROPOGENIC PARTICULATE MATTER HAIFA METROPOLITAN AREA, ISRAEL AND ITS RELATION TO THE SYNOPTIC CONDITIONS AND THE SUMMER CLIMATIC STRESS
}

\author{
H. SAARONI ${ }^{1}$ E. LEVI ${ }^{1}$ B. $Z I V^{2}$
}

\begin{abstract}
Natural and Anthropogenic Particulate Matter Haifa Metropolitan Area, Israel and Its Relation to the Synoptic Conditions and the Summer Climatic Stress. Relatively high Particulate Matter (PM) concentration characterizing the Middle East and Israel are attributed mainly to natural dust storms, but also to local and remote anthropogenic sources. The spatio-temporal distribution of the pollution highly depends on the geographical characteristics of the region, such as the complex terrain of Haifa, the nearby bay structure and the atmospheric conditions determined by the combined meso-, local and synoptic-scale circulations. The research analyzes the role of synoptic conditions and climatic stress in the temporal and spatial distribution of $\mathrm{PM}_{10}$ and $\mathrm{PM}_{2.5}$, adopting the 'environment to circulation' approach. The study focuses on the summer season, characterized by the persistent northwesterly Etesian winds, with no dust import from the Sahara or the Arabian deserts. A pronounced diurnal and weekly course of PM concentrations indicate its anthropogenic sources, both local and remote. PM concentrations were found positively correlated with the summer climatic stress index, developed by Saaroni et al. (2017). High climatic stress conditions are characterized by weakening of the Etesian winds and a thinner boundary layer over Israel. This reduces the transport of remote pollution from East Europe on the one hand, but enhances locally originated pollution on the other, due to the implied weakening of their removal mechanisms. An increase in the climatic stress is well noted along the study period, 2002-2017, associated with the general warming. Nevertheless, a significant reduction trend in the daily summer concentrations of $\mathrm{PM}_{10}$ and $\mathrm{PM}_{2.5}$ is found, attributed to the dominant role of the regulations in reducing air pollution. This negative trend is accompanied by relatively high inter-annual variability, which reflects the dependence of concentrations on the climatic stress.
\end{abstract}

Keywords: Particulate Matter (PM), dust outbreaks, heat stress, climatic stress, Israel.

\section{INTRODUCTION}

High Particle Matter (PM) concentration are detected over the Middle East and Israel, attributed to natural dust outbreaks as well as to local and remote anthropogenic sources (e.g., Dayan et al., 1991, 2008; Erel et al., 2007, 2013; Pey et al., 2013; Dayan et al. 2017). Epidemiological studies demonstrated that PM has a

\footnotetext{
${ }^{1}$ Department of Geography and the Human Environment, School of Geosciences, Tel Aviv University, Israel, Email: saaroni@post.tau.ac.il

${ }^{2}$ Department of Natural Science, The Open University of Israel, Ra'anana, Israel
} 
clear correlation with the number of daily deaths and hospitalizations (e.g., Eitan et al., 2010; Karanasiou et al., 2012; Kloog et al., 2013) as well as with environmental variables, such as poor visibility (Erel et al., 2013). EPA (2013) states that inhalable particles, including coarse $\left(\mathrm{PM}_{10}\right)$ and especially fine $\left(\mathrm{PM}_{2.5}\right)$ particles, originate mostly from anthropogenic sources and $\mathrm{PM}_{10}$ concentration are highly correlated with these of $\mathrm{PM}_{2.5}$.

The spatio-temporal distribution of air pollution is highly dependent on the atmospheric conditions determined by the combined local, meso- and synoptic-scale circulations, together with the geographical characteristics of the region, i.e., the complex terrain of Haifa metropolitan area and the nearby bay structure (Fig. 1). Yuval and Broday (2006) showed that while dust outbreaks are excluded, heavy traffic load is the main source for $\mathrm{PM}_{10}$ in the Haifa metropolitan area, though this area has major industrial plants, including the national petroleum refineries, petrochemical and agrochemical industries.

The present study analyzes the relationships between synoptic conditions and the distribution of $\mathrm{PM}_{10}$ and $\mathrm{PM}_{2.5}$ in Haifa metropolitan area. It aims to characterize the temporal PM regime, focusing on the summer, and in particular, to examine its relationship with the summer climatic stress (CSI). The 'environment to circulation' approach is adopted following Yarnal (1993), Yarnal et al. (2001) and Dayan et al. (2012), who showed it as efficient tool in relating synoptic conditions to local air pollution.

\section{METHODOLOGY}

Study region: The Haifa metropolitan area, located at the eastern Mediterranean (EM) coastline (Fig. 1), is the third largest metropolitan area of Israel. The Haifa Bay is the center of commerce and industry, including the Port of Haifa. It has a population of almost 1 million, and is the major regional center for the northern part of the country. The city is built mostly on the northern slopes of Mount Carmel, reaching an altitude of $\sim 500 \mathrm{~m}$ above sea level.

Database: The study is based on $\mathrm{PM}_{10}$ and $\mathrm{PM}_{2.5}$ measurements from monitoring stations of the Ministry of Environmental Protection ( 7 station of $\mathrm{PM}_{10}$ and 3 of $\mathrm{PM}_{2.5}$ ) and wind data - from 5 stations (see Fig. 1), for all seasons between 2002 and 2012, and for the summer season up to 2017. For the main part of the study, devoted to the summer, we adopted the synoptic definition of Alpert et al. (2004a,b), according which the summer is the period during which the Persian Trough, associated with the Etesian winds, dominates, i.e., between 25 of June and 7 of September. This period is entitled hereafter, the 'synoptic summer'. The classification of the summer days is based on the climatic stress index (CSI), developed by Saaroni et al. (2017). This index is calculated based on a prediction equation (i.e., a regression model) that combines the normalized and standardized national heat stress and the height of the persistent marine inversion. The potential predictors for building the prediction equation were comprised of atmospheric variables found correlated with these two weather attributes together with indices representing synoptic to large-scale features, derived through a composite maps analysis of days with extreme values of these attributes. The synoptic-scale 
potential predictors were expressed as average values over specific regions or as the difference between key geographical points reflecting dipole structures. The statistical downscaling was based on multi-regression procedures of the Statistical Package for the Social Sciences (SPSS) software, using the linear stepwise method. The regression equations derived were first verified through cross-validation, using the "holdout validation" technique, than we calculated the squared correlation between the observed and predicted values $\left(\mathrm{R}^{2}\right)$ and the Standard Error (SE). Finally, the skill score (Wilks, 2011), that estimates the relative advantage of a regression model with respect to an alternative, "reference prediction", was calculated. In addition to the above validation procedure, the prediction equation, which was based on data from 1976-2008, was applied on an independent sample of summers from 2009-2012. This was done also to assess the stability of the regression model under the warming trend observed in the region (Ziv and Saaroni, 2011; Sohami et al., 2011).

The spectrum of the calculated daily CSI values was divided into three parts of equal size, used as the basis of the new synoptic types, defined as: "comfort" (CSI1), "medium" (CSI2) and "discomfort" (CSI1). The attribution of a certain day to one of these types is determined according to its calculated CSI.

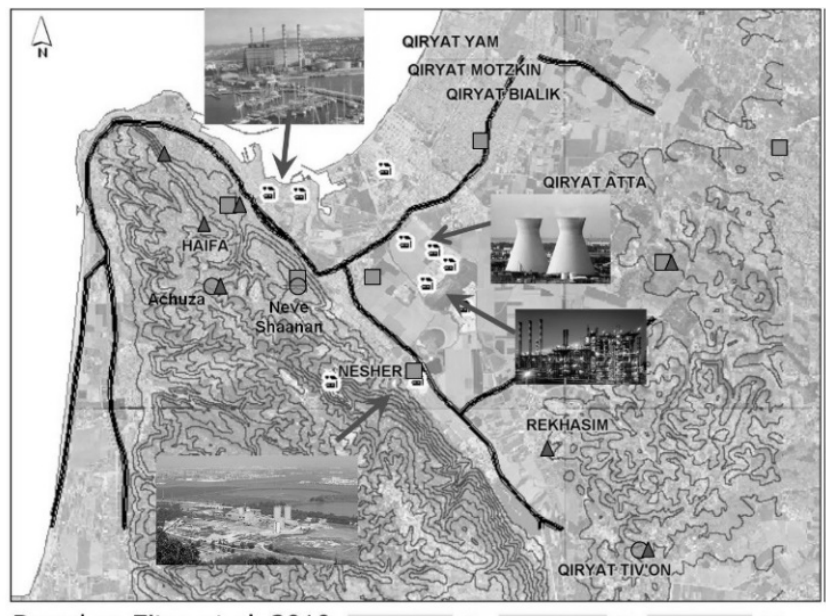

Fig. 1. The Haifa metropolitan area, together with the location of the wind, $P M_{10}$ and PM2.5 monitoring stations and main local pollution sources

Based on Eitan et al. 2010

Methods: Boxplot charts are used to present the seasonal distribution of daily $\mathrm{PM}_{10}$ and $\mathrm{PM}_{2.5}$ concentration through their quartiles. Exceeding days are defined as days in which the daily average concentration exceeded the Israeli standard, being $130 \mu \mathrm{g} / \mathrm{m}^{3}$ for $\mathrm{PM}_{10}$ and $37.5 \mu \mathrm{g} / \mathrm{m}^{3}$ for $\mathrm{PM}_{2.5}$, in at least one station. Their distribution is studied on a daily, weekly and seasonal basis. For the summer season, we analyzed the relation between PM concentrations and the degree of climatic stress as well as the long-term variations and trends of PM concentrations and of the CSI from 2002-2017, using linear regressions (t-test). The analysis of the synoptic conditions of the days representing high and low PM concentration was done through composite anomaly maps, for various atmospheric variables, based on the NCEP/NCAR analysis database (Kalnay et al., 1996; Kistler et al., 2001). 


\section{RESULTS}

\subsection{Seasonal distribution}

The seasonal distribution of $\mathrm{PM}_{10}$ and $\mathrm{PM}_{2.5}$ (Fig. 2) indicates that the summer season (JJA) has the lowest concentrations and the smallest variation with respect to the other seasons. The spring season has the highest number of exceeding days, $9.8 \%$ and $16.2 \%$ for $\mathrm{PM}_{10}$ and $\mathrm{PM}_{2.5}$, respectively, compared to $7.4 \%$ and $12.6 \%$ of the days for the winter. Daily maximum $\mathrm{PM}_{10}$ concentration of $1366 \mu \mathrm{g} / \mathrm{m}^{3}$ was measured during a severe winter dust event (25-27 Feb. 2006, see Fig. 3a) and the daily $\mathrm{PM}_{2.5}$ concentration was $493 \mu \mathrm{g} / \mathrm{m}^{3}$. The autumn season (SON), though experiencing dust events, has $2.9 \%$ and $7.9 \%$ exceeding days for $\mathrm{PM}_{10}$ and $\mathrm{PM}_{2.5}$, respectively. Surprisingly, the most severe and longest dust storm in Israel during the study period occurred in the beginning of the autumn season, 7-12 of September 2015 (see Fig. 3b), which is exceptional for the end of the summer season. The dust, originated from Iraq and Syria, was transported by northeasterly lower-level winds associated with a Red Sea Trough (Kelley et al., 2015; Parolari et al., 2016; Gasch et al., 2017). The average daily maximal value measured at the Haifa Bay was 1829.2 $\mu \mathrm{g} / \mathrm{m}^{-3}$ for $\mathrm{PM}_{10}$ and $459.6 \mu \mathrm{g} / \mathrm{m}^{-3}$ for $\mathrm{PM}_{2.5}$ (data taken from the website of The Ministry of Environmental Protection, http://www.svivaaqm.net/Default.rtl.aspx). This dust storm is not included in the database of Fig. 2. In the summer, in spite of the persistent stability and absence of rain during the entire season, PM concentration are the lowest, and only three exceeding days (in 10 seasons, $0.3 \%$ ) for $\mathrm{PM}_{10}$ were measured, with maximum daily concentration of $151.7 \mu \mathrm{g} / \mathrm{m}^{3}$. These were mostly dust events that occurred in June. For $\mathrm{PM}_{2.5}$ there were $4.2 \%$ exceeding days with maximum daily concentration of $54.6 \mu \mathrm{g} / \mathrm{m}^{3}$ (see Fig. 3c), which shows no dust over the study area. Erel et al. (2007) showed that transport of anthropogenic PM from Greece and east Europe characterizes the summer in Israel.
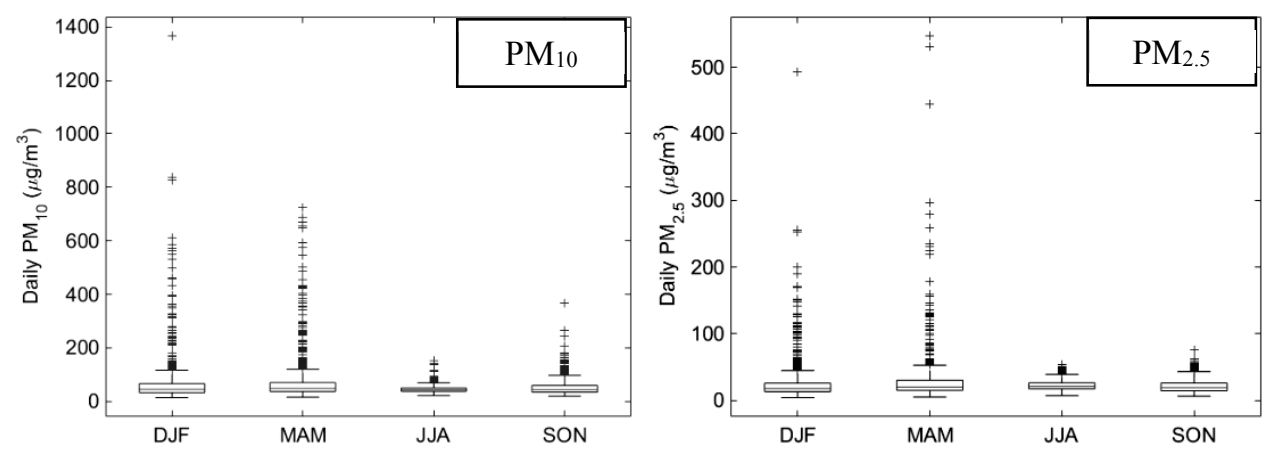

Fig. 2. Boxplot charts of the seasonal distribution of daily PM10 (left) and PM 2.5 (right) concentration $\left(\mu \mathrm{g} / \mathrm{m}^{-3}\right)$ of the most polluted station in the Haifa metropolitan area, for the period 2002/3-2011/12. The differences in the average concentration among the seasons are statistically significant (according t-test) for both $P M_{10}$ and $P M_{2.5}$. 

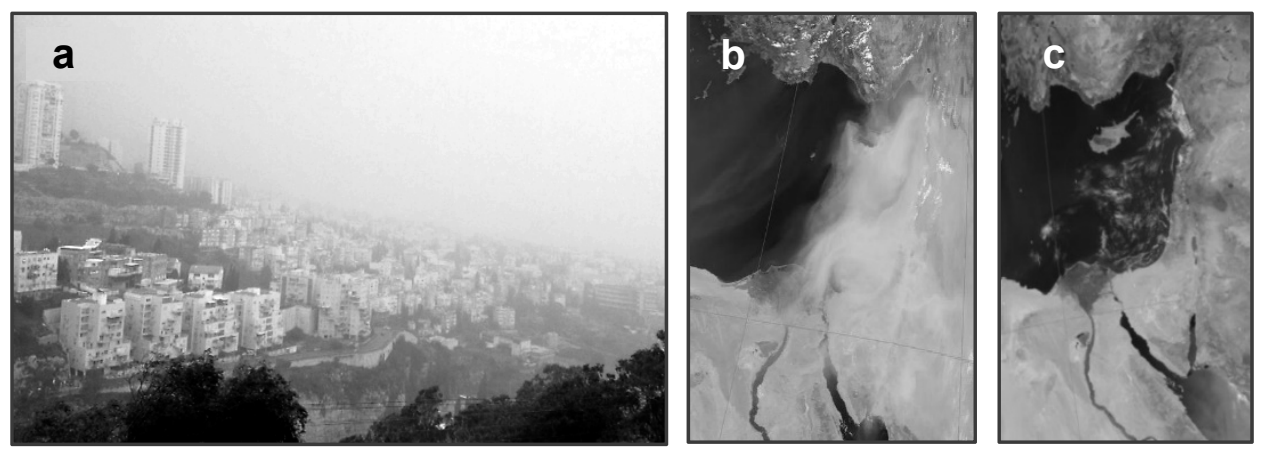

Fig. 3. Haifa during a severe dust event, 11 Feb 2015 (a) the AquaMODIS satellite image of the most severe dust event, 8 Sep 2015 (b) and of the summer day with the highest PM2.5 concentration, 1 Jul 2003 (c)

PM pollution events in the study region are associated with different synoptic systems, including cyclonic and anticyclonic ones. Extreme dust events result from natural dust outbreaks originating from the Sahara and Arabian deserts (see Figs. 3a and 3b), mostly associated with Cyprus lows and North African ('Sharav') lows (Alpert and Ziv, 1989; Dayan et al., 1991; Dayan et al., 2008), as well as under the Red Sea trough, as noted above (see Fig. 3b). Nevertheless, several exceeding days occurred also during the summer, but they were characterized by much lower PM concentration. A MODIS satellite image of the summer day with the highest $\mathrm{PM}_{2.5}$ concentration, $54.6 \mu \mathrm{g} / \mathrm{m}^{3}$ (July $1^{\text {st }}, 2003, \mathrm{PM}_{10}$ was $50 \mu \mathrm{g} / \mathrm{m}^{3}$ ), indicate the large difference from a typical dust event (compare Figs. $3 \mathrm{~b}$ and $3 \mathrm{c}$ ).

When the exceeding days are excluded, a different seasonal distribution is noted, especially for $\mathrm{PM}_{2.5}$ (Fig. 4). The summer becomes the most polluted season for $\mathrm{PM}_{2.5}$, whereas for $\mathrm{PM}_{10}$ the highest average and maximum concentration remains in the winter and spring seasons, but the differences between the various seasons become smaller. The summer PM, especially that of $\mathrm{PM}_{2.5}$, has been attributed to local and remote anthropogenic sources (Erel et al., 2007; Dayan et al., 2017).
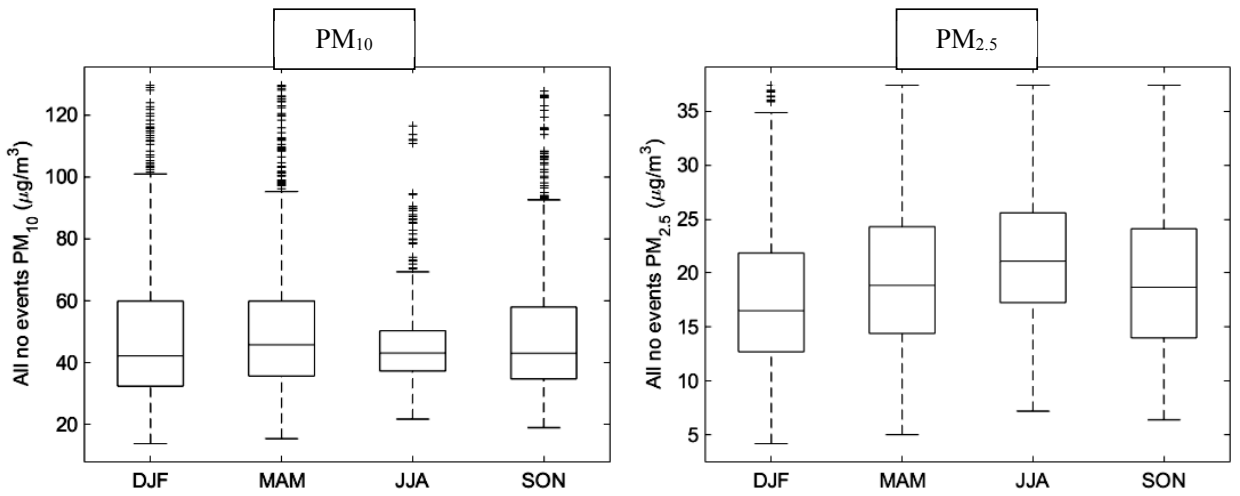

Fig. 4. As in Fig. 2 but without exceeding days 


\subsection{Summer characteristics}

A persistent synoptic system, the Persian Trough, accompanied by the northwesterly Etesian winds, prevails during the summer and is characterized by small inter-diurnal variations (Ziv et al., 2004; Harpaz et al., 2014). The Etesian winds cause relatively cool and moist advection to Israel within a shallow boundary layer, of about 700 meters. Above, there is hot and dry air subsidence. The combination of the two processes results in a persistent marine inversion (Bitan and Saaroni, 1992; Dayan et al., 1988, 2002; Ziv et al., 2004), which blocks the lower-level convection and the vertical dispersion of pollutants. The dominance of the Etesian winds prevents the EM and the Levant region from being affected by dust outbreaks during the summer (see, for example, Dayan et al., 2008 and Table 2 in Ganor et al., 2010).

\subsubsection{Temporal variations}

The average daily PM concentration for each day of the week in the summer (not shown) indicates a clear weekly course, for both $\mathrm{PM}_{10}$ and $\mathrm{PM}_{2.5}$, with a minimum on Saturday. This course can be regarded as a footprint of local contribution, since Saturday is the main sabbatical day in Israel. Moreover, an analysis of the diurnal course of $\mathrm{PM}_{2.5}$ (not shown) indicates a major peak in the early hours of the morning, corresponding to the morning rush hour, and a secondary peak in the evening rush hour.

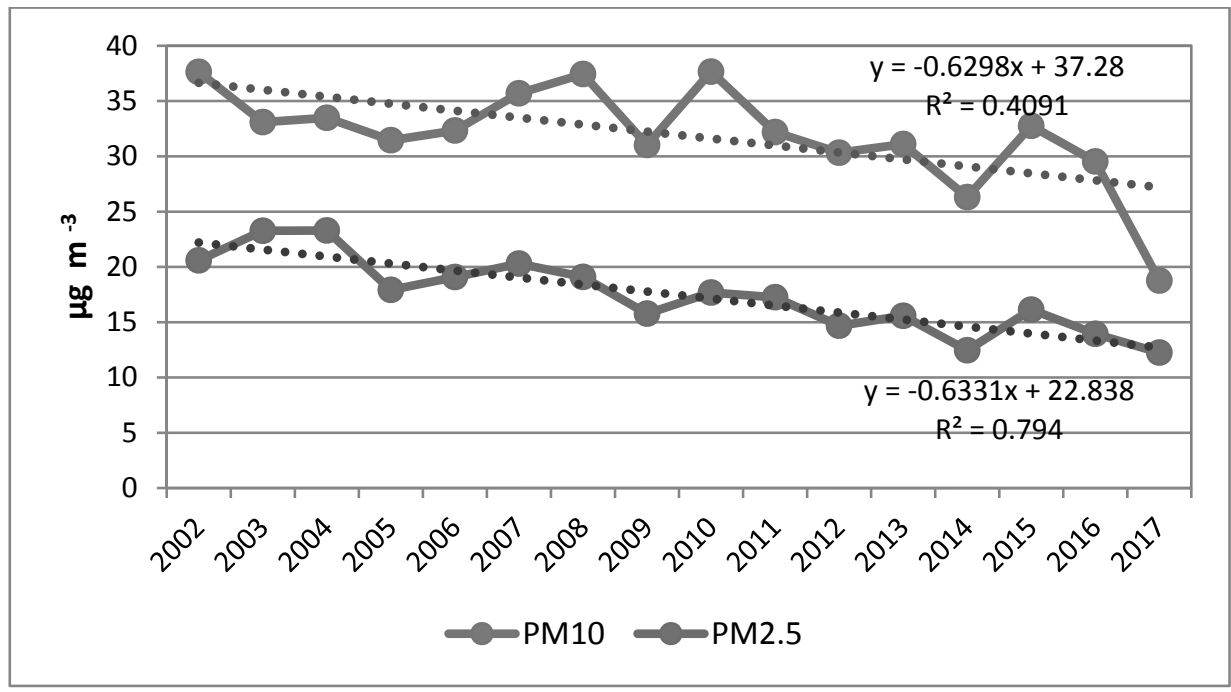

Fig. 5. The long-term trend of the daily average PM 10 (blue) and PM 2.5 (red) concentration ( $\left.\mu \mathrm{g} \mathrm{m}^{-3}\right)$, for the synoptic summer seasons, 2002-2017, at the Neve Sha'anan station. The dotted lines represent the linear regression line

The long-term trend along the 16 seasons, 2002-2017, was calculated for the Neve Sha' anan station, measuring both $\mathrm{PM}_{10}$ and $\mathrm{PM}_{2.5}$ (Fig. 5). In spite of the large 
inter-annual variability, the linear regression line shows a significant negative trend (at the 0.01 level) for both, $\mathrm{PM}_{10}$ and $\mathrm{PM}_{2.5}$, reflecting a general improvement in the air quality. The reduction trend seen in PM concentration is in the opposite direction of the significant regional warming along this period (not shown), which is expected to aggravate air pollution. This expectation is supported by the relatively high concentration observed in the warmest summers that exhibited high climatic stress, i.e., 2010 and 2015.

\subsubsection{The relations between summer PM concentration and the CSI}

The daily concentration of $\mathrm{PM}_{10}$ and $\mathrm{PM}_{2.5}$ were correlated with the summer climatic stress index (CSI). The boxplot distribution (Fig. 6) indicates that the average daily concentration increases with the CSI. The correlation $(R)$ calculated between the PM and the CSI is +0.41 for $\mathrm{PM}_{10}$ and +0.31 for $\mathrm{PM}_{2.5}$, both significant at the 0.01 level. Since the standard deviations of the three groups (not shown) are larger than the differences among them, one may conclude that the particle pollution is not effectively distinguishable by the CSI categorization. However, when looking at the distribution of $\mathrm{PM}_{10}$ (Fig. 6, left) a substantial difference is noted for the CSI categories, expressed in the number of outliers beyond the upper inner fence. For the CSI1 there are no outliers, for CSI2 four outliers and for CSI3 over fifteen. A similar trend, though much less pronounced is seen for the $\mathrm{PM}_{2.5}$. This further indicates that heavy climatic stress aggravates PM pollution. But, it may also suggest that some of these events are associated with transported dust (expressed mainly in increased $\mathrm{PM}_{10}$ ), resulting from the 'tropical' type of extremely high summer temperatures (Harpaz et al., 2014).
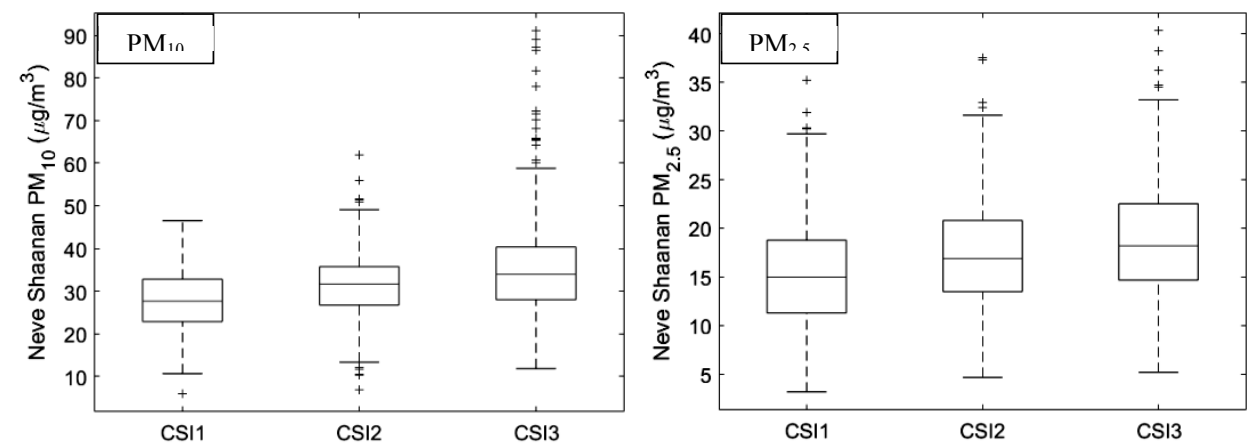

Fig. 6. Distribution of daily values ( $\mu \mathrm{g} \mathrm{m}^{-3}$ ), of PM10 (left) and PM 2.5 (right) according to the CSI, at the Neve Sha'anan station, during all days of the synoptic summer period, 2002-2017

In order to demonstrate the relation between PM concentration and the atmospheric conditions, the lower-level (850-hPa) temperature anomaly maps for the lowermost and uppermost tenths of the days for $\mathrm{PM}_{10}$, are presented (Fig. 7). A 
negative anomaly is well seen over the majority of the Mediterranean for the lowermost tenths (Fig. 7a), in contrast with the widespread positive anomaly centered over the EM for the uppermost tenths (Fig. 7b). The positive temperature anomaly in days with high PM concentration, and vice versa, agrees with Saaroni et al. (2017) who found that the major predictor for the climatic stress in Israel is the lower-level temperature. It should be noted that the majority of the area seen in the maps is covered by positive anomalies. This goes in line with the above-normal temperatures found for the study period compared to the reference period (19812010). Most similar results were found for $\mathrm{PM}_{2.5}$.
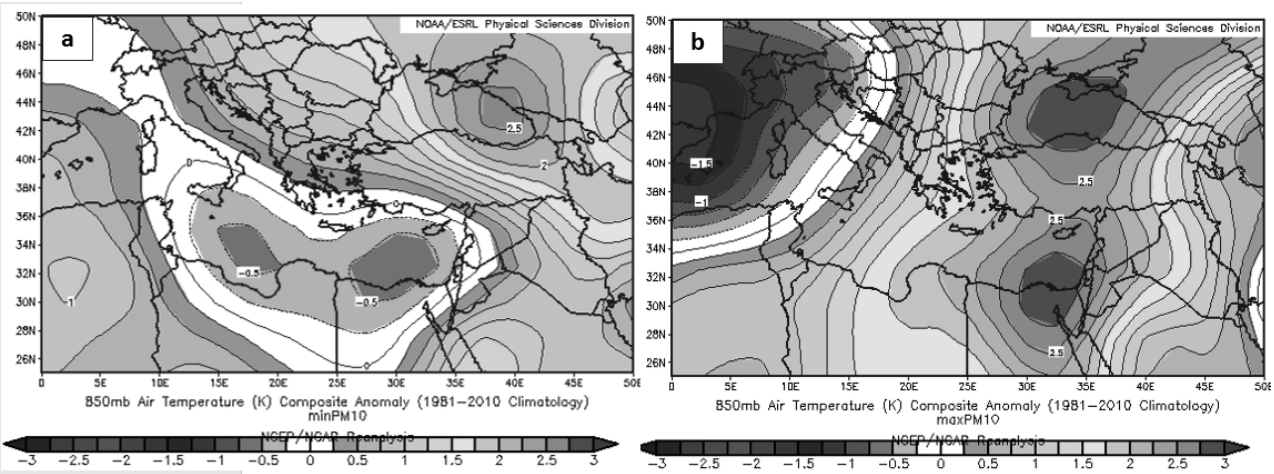

Fig. 7. Composite maps of the 850-hPa temperature anomaly for the lowermost (a) and uppermost (b) tenths of the PM10, measured at the Neve Sha'anan station

A signature of a weakening of the Etesian winds for the uppermost tenth of $\mathrm{PM}$ days is noted in the 925-hPa level (not shown). This implies a reduction of the transport of PM from East Europe (Erel et al., 2007), together with an enhancement of local pollution due to the implied weakening of their removal by horizontal dispersion.

\section{SUMMARY}

Haifa metropolitan area is subjected to high particle Matter (PM) concentration attributed to natural dust outbreaks as well as to local and remote anthropogenic sources. The analysis of the seasonal course showed that the winter and spring are the richest with PM pollution, with days of severe dust outbreaks, associated with Cyprus and North African ('Sharav') lows. Nevertheless, dust storms appear also during the autumn, in which the most severe storm (7-12 September 2015) occurred, under a Red Sea trough. Dust storms do not appear in the summer, and therefore the average concentration, and the variability, of PM are the smallest. While excluding events in which the PM concentration exceed the Israeli standard, the highest average of fine particles, $\mathrm{PM}_{2.5}$, appears in the summer season.

For the summer season, the synoptic conditions, the wind regime and the diurnal 
and weekly course of PM concentration reflect the dominance of the anthropogenic sources. PM concentration is found to be positively, and significantly, correlated with the CSI, indicating that severe discomfort conditions are accompanied by higher PM pollution. The weakening of the Etesian winds in days with high CSI is expected to reduce imported PM concentrations. This and the lowering of the marine inversion in such days are expected to enhance PM pollution from local sources due to weakening of the dispersion mechanisms. The actual aggravation of PM pollution in these days indicates that local PM sources are dominant.

An increase in the climatic stress, associated with the global and regional warming, is well noted along the study period, 2002-2017. Nevertheless, a significant reduction in the daily summer concentration of $\mathrm{PM}_{10}$ and $\mathrm{PM}_{2.5}$ is found. This is attributed to the effectivity of the regulations in reducing air pollution from vehicles and factories during the study period.

The positive correlation, found between the climatic stress and PM pollution, and the aggravation in the climatic stress, associated with the global warming, necessitate tightening the control of anthropogenic sources. The synoptic classification according the CSI, which is based on the 'environment to climate' approach, is found to be effective for explaining inter-diurnal and inter-annual variations in PM pollution.

\section{Acknowledgment}

The authors wish to thank the Smaller-Winnikow Foundation, the Israeli Science Foundation (ISF, grant numbers 597/13 and 1123/17) that funded this study.

\section{REFERENCES}

1. Alpert P., Ziv B. (1989), The Sharav cyclone: Observations and some theoretical considerations. Journal of Geophysical Research 94(18), 495-518.

2. Alpert P., Osetinsky I., Ziv B., Shafir H. (2004a), Semi-objective classification for daily synoptic systems: application to the eastern Mediterranean climate change. International Journal of Climatology 24, 1001-1011.

3. Alpert P., Osetinsky I., Ziv B., Shafir H. (2004b), A new seasons definition based on classified daily synoptic systems: an example for the eastern Mediterranean. International Journal of Climatology 24, 1013-1021.

4. Bitan A., Saaroni, H. (1992), The horizontal and vertical extension of the Persian Gulf trough. International Journal of Climatology 12, 733-747.

5. Dayan U., Shenhav, R., Graber, M (1988), The spatial and temporal behavior of the mixed layer in Israel. Journal of Applied Meteorology 27, 1382-1394.

6. Dayan U., Heffter J., Miller J., Gutman G. (1991), Dust intrusion events into the Mediterranean Basin. Journal of Applied Meteorology 30, 185-199.

7. Dayan U., Lifshitz-Goldreich, B., and Pick, K. (2002), Spatial and structural variation of the atmospheric boundary layer during summer in Israel-Profiler and rawinsonde measurements, Journal of Applied Meteorology 41, 447-457.

8. Dayan U., Ziv B., Shoop T., Enzel Y. (2008), Suspended Dust over South-Eastern Mediterranean and its Relation to Atmospheric Circulations. International Journal of Climatology 28, 915-924. 
9. Dayan U., Tubi A., Levy I. (2012), On the importance of synoptic classification methods with respect to environmental phenomena. International Journal of Climatology 32, 681-694.

10. Dayan U., Ricaud P., Zbinden R., Dulac, F. (2017), Atmospheric pollution over the eastern Mediterranean during summer - a review. Atmospheric Chemistry Physics 17, 13233-13263.

11. Eitan O., Yuval., Barchana M., Dubnov J., Linn S., Carmel Y., Broday D. (2010), Spatial analysis of air pollution and cancer incidence rates in Haifa Bay, Israel. Science of the Total Environment 408, 4429-4439.

12. EPA (2013), United States Environmental Protection Agency website https://www.epa.gov/pm-pollution (accessed on 6 February, 2018)

13. Erel Y., Kalderon-Asael B., Dayan U., Sandler A. (2007), European atmospheric pollution imported by cooler air masses to the Eastern Mediterranean during the summer. Environmental Science \& Technology 41, 5198-5203.

14. Erel Y., Tirosh O., Kessler N., Dayan U., Belkin S., Stein M., Sandler A., Schauer J.J. (2013), Atmospheric Particulate Matter (PM) in the Middle East: Toxicity, Trans-boundary Transport, and Influence of Synoptic Conditions. In: Censi P., Darrah T., Erel Y. (eds) Medical Geochemistry. Springer, Dordrexht, 31-46.

15. Ganor E., (2010), Osetinsky I., Stupp A., Alpert P. (2010), Increasing trend of African dust, over 49 years, in the eastern Mediterranean. Journal of Geophysical Research 115, D07201, doi:10.1029/2009JD012500.

16. Gasch P., Rieger D., Walter C., Khain P., Levi Y., Knippertz P., Vogel B. (2017), Revealing the meteorological drivers of the September 2015 severe dust event in the Eastern Mediterranean. Atmospheric Chemistry and Physics 17, 13573-13604.

17. Harpaz T., Ziv B., Saaroni H., Beja E. (2014), Extreme summer temperatures in the East Mediterranean -dynamical analysis. International Journal of Climatology 34, 849-862.

18. Kalnay E., Kanamitsu M., Kistler R., Collins W., Deaven D., Gandin L., Iredell M., Saha S., White G., Woollen J., Zhu Y., Chelliah M., Ebisuzaki W., Higgins W., Janowiak J., Mo K.C., Ropelewski C. ,Wang J., Leetmaa A., Reynolds R., Jenne R., Joseph D. (1996), The NCEP/NCAR 40-Year Reanalysis Project. Bulletin of the American Meteorological Society 77, 437-471.

19. Karanasiou A., Moreno N., Moreno T., Viana M., Leeuw F.,Querol X. (2012), Health effects from Sahara dust episodes in Europe: Literature review and research gaps. Environment International 47, 107-114.

20. Kelley C.P., Mohtadi S., Cane M.A., Seager R., Kushnir Y. (2015), Climate change in the Fertile Crescent and implications of the recent Syrian drought. Processings of National Academy of Sciences 112(11), 3241-3246.

21. Kistler R., Kalnay E., Collins W., Saha S., White G., Woollen J., Chelliah M., Ebisuzaki W., Kanamitsu M., Kousky V., Van Den Dool H., Jenne R., Fiorino M. (2001), The NCEP-NCAR 50-year reanalysis: Monthly means CD-ROM and documentation. Bulletin of the American Meteorological Society 82, 247-267.

22. Kloog I., Ridgway B., Koutrakis P., Coull B.A., Schwartz J.D. (2013), Long- and Short-Term Exposure to PM2.5 and Mortality. Epidemiology 24, 555-561.

23. Parolari A.J., Li D., Bou-Zeid E., Katul G.G., Assouline S. (2016), Climate, not conflict, explains extreme Middle East dust storm. Environmental Research Letters 11, 114013 doi:10.1088/1748-9326/11/11/114013.

24. Pey J., Querol X., Alastuey A., Forastiere F., Stafoggia M. (2013), African dust outbreaks over the Mediterranean Basin during 2001-2011: PM10 concentrations, 
phenomenology and trends, and its relation with synoptic and mesoscale meteorology. Atmospheric Chemistry and Physics 13, 1395-1410.

25. Saaroni H., Savir A., Ziv B. (2017), Synoptic classification of the summer season for the Levant using an "environment to climate" approach. International Journal of Climatology DOI: 10.1002/joc.5116

26. Sohami D., Dayan U., Morin E. (2011), Warming and drying of the eastern Mediterranean: additional evidence from trend analysis. Journal of Geophysical Research, Atmosphere 116, 1-12.

27. Wilks D.S. (2011), Statistical Methods in the Atmospheric Sciences. $3^{\text {rd }}$ ed. Elsevier: Amsterdam.

28. Yarnal B. (1993), Synoptic Climatology in Environmental Analysis. Belhaven Press: London.

29. Yarnal B., Comrie A.C., Frakes B., Brown D.P. (2001), Developments and prospects in synoptic climatology - Review. International Journal of Climatology 21, 1923-1950.

30. Yuval, Broday D.M. (2006), High-resolution spatial patterns of long-term mean concentrations of air pollutants in Haifa Bay area. Atmospheric Environment 40, 3653-3664.

31. Ziv B., Saaroni H., Alpert P. (2004), The factors governing the summer regime of the eastern Mediterranean. International Journal of Climatology 24, 1859-1871.

32. Ziv B., Saaroni H. (2011), The contribution of moisture to heat-stress in a period of global warming: the case of the Mediterranean. Climatic Change 104(2), 305-315. 